\title{
Discussion on path construction of humanistic quality education for Chinese young athletes
}

\author{
ZHANG Fan \\ Department of Police Skills and Tactics, Nanjing Forest Police College \\ Sports Science postdoctoral programme, Nanjing Normal University \\ Nanjing 210023, China \\ zhangfan@nfpc.edu.cn
}

\begin{abstract}
Currently, too much emphasis on the physical and psychological qualities as well as skills and tactics and the underestimation of cultivating other quality led to the powerlessness of young athletes in competitive sports and the poor comprehensive quality so that there even emerged some negative behaviors made by them in the society. The main reason of those phenomena lay in the absence of bringing the athletes' subjectivity into full play and the neglecting of cultivating their humanistic qualities. Therefore, with the purpose of satisfying the sports development requirements in the "New Normal" , this paper deconstructed and remodeled the problems of young athletes in humanistic quality education. The practical and achievable action plans were put forward to practice the principles of training young athletes whose value orientations were "First to be a good person and then to be a talent" and "Education and Medal" through constructing corresponding educational paths with the emphasis on both quantity and quality.
\end{abstract}

Keywords—humanistic education; young athletes; sports talents; humanistic quality

\section{INTRODUCTION}

As the essence of competitive sports, "Education and Medal" followed the demands of time when the humanity integrated with the sports. Its ultimate goal was to realize the people's subjectivity in carrying out the universal ethical values featuring justice, equality and harmony and apply humanity in winning the gold medal. The construction of a sports power called for the emphasis on the overall development of athletes for the national image as well as the image of athletes could be projected by their comprehensive quality in the future. It's the fundamental requirement of humanism in winning the gold medal to have a clear break with the narrow training mode of competitive sports. If the humanistic quality education of youth athletes can be improved to full potential from different perspectives and the corresponding education path can be established, it is able to fully reflect the subject value of humanity and promote the sustainable development of competitive sports' talent training.

\section{RELATIONS to BE GRASPED IN CONSTRUCTING PATHS FOR YOUNG ATHLETES' HumANiSTIC QUALITY EDUCATION}

\section{A. Relation between Humanistic Quality Education and Professional Quality Education}

Both humanistic and professional quality education were important parts in quality-oriented education of young athletes while the former emphasized the education value on a psychological level and the latter emphasized the tools property for skills and tactics so that the combination of both was beneficial to the stable improvement of young athletes' professional quality and other qualities. Thus we should put emphasis on the training the sports skills and teaching major culture courses and fully explored its inner humanistic values. What's more, along with knowledge instruction and exercise training, we ought to find its inner spiritual connotations such as the pursuit of truth and rationality.

\section{B. Relation between Humanism and Medal-oriented Education}

Currently the training of young athletes was still medal-oriented, so how to change this situation? With the application of various education forms, we needed to guide young athletes to practice self-improvement, turn the excellent cultural achievements into own experience, build the stable humanistic knowledge and thoughts and develop humanistic spirits and perfect personalities so as to cultivate the outstanding athletes of excellent physical quality and sound psychological quality. The most feasible way was to reform the educational contents. That is to say, to increase the proportion of humanistic quality education in the cultivation as a breakthrough and carry forward the current education to humanistic quality education gradually.

\section{Relations between Humanistic Education and Professional Education}

The humanistic education and professional education were relative and jointly formed two attributes of young athletes cultivation. The purposes of humanistic education were to promote the formation, development and sublimation of the humanity so 
that athletes could explore and ponder over the meaning of lift in the works taken on the personal, comprehensive and historical development [1]. The purposes of professional education lay in the preparation for the perfection of young athletes' career, the search for excellent athletes to make contributions to the progress and take-off of the sports undertakings and the cultivation of excellent people for the country and their families. The humanistic education of excellent young athletes was not in contradiction with the professional elements of competitive sports, instead they agreed with each other. The humanistic education and professional education based on the demand of humanism and professionalism were indispensable in the personal development and sports undertakings as well as the demand of the society. Some people held the wrong idea that the humanistic quality was useless for athletes' careers, which was equivalent to the thinking of separating the humanistic spirits and thoughts from the professional training. The thought of "Winning the gold medal first" was a false practice in pure professional training which lacked the education of humanistic spirits.

With the main purpose of cultivating young athletes of high quality, sports colleges and universities should fully demonstrate their humanistic characteristics in education. The government should make policies to implement the constructions in an all-round way and set basic goals of reform in the field of humanity [2]. The humanistic care ought to be highlighted in school management and environment construction. The humanistic knowledge, professional education and training knowledge should be combined as the core of the training as far as the training of teacher and coaches was concerned. The construction of humanity courses was essential and served as the core course in the field of course construction. As for the teaching and training evaluation, the development of humanistic quality should play an important role in the comprehensive evaluation of young athlete's cultivation quality, so that the corresponding basic index system of education and its supporting evaluation strategies ought to be formulated.

Among those measures, we needed to contemplate and relocate immediately the values, purposes and methods of humanistic quality education for young athletes. Every related teaching staff should have a clear understanding about the key roles of humanistic spirits, knowledge and quality in the development of individuals and society and key roles of humanistic quality education in the training system of young athletes. As for the purpose of humanistic quality education, it should have a clear break with the command of concepts, facts, theories and techniques so that the young athletes could have a humanistic reflection on themselves, cultural education and the sports training. Their inner humanistic demand should be awakened, basic humanistic quality cultivated, high-toned humanistic ideals and corresponding spirits formed. Therefore, they would be more critical and determined to reject decadent thoughts such as consumerism, utilitarianism, hedonism, fully aware of the beauty of humanity and the noble dignity. Specifically, the means of humanistic quality education should be free from the simple cramming education, superficial sermon and training brought by the basic attributes of humanistic knowledge. With strong reflectivity, the humanistic knowledge harbored the content of subjectivity and individuality and its emphasis was not constrained by the simple commanding of the knowledge. Therefore, in order to inspire the real attention and reflection of young athletes, the effective means of humanistic quality education lay in the form of bilateral interaction between discussion and dialogue, practice and reflection.

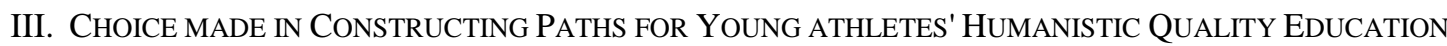

\section{A. Fundamental Change of Utilitarian and Biased Value on Competitive Sports}

As the participant in both sports and social undertakings, the young athlete, an organic unity of knowledge, emotions, wills and actions, was the epitome of competitive sports. Thus the cultivation of the young athletes should be based on the existing sports training and transcend the previous limitation and unifaciality of training-oriented mode so as to vigorously promote the humanistic quality education. Under that circumstance, the young athletes would possess the truth, good, and beautiful characters and have a perfect personality with a fully developed connotation such as knowledge, skills and attitudes [3]. For a long time, the utilitarianism of sports was overemphasized and the non-utilitarianism was neglected. The utilitarian aspect lay in the profits brought by the winning such as the job opportunity and the change of social position. The non-utilitarian aspect fell on the benefits of the sports such as character molding, sports spirits elevation, will character improvement, the enrichment of cultural life and harmonious interpersonal relationships [4]. Essentially speaking, the influence of education on people's development mainly exerted by the humanistic quality education gradually. Lowering the interaction between them would bring about the losing of excellent morality and ideology as well as the feeling of social mission, the unstable basis of social intercourse and the inner cultivation, especially in the field of competitive sports. Thus we should change the biased value of utilitarianism in competitive sports, follow the principle of equal attention to the sports training and humanistic education, deepen the reform of young athletes' cultivation mode so that the previous vicious circle of "Materials before People" as well as "Appreciating the sport performance rather than the humanistic quality" would be changed. Consequently, the outlook of sports talents cultivation would be formed as "Paying equal attention to people and materials while the former was further highlighted” .

\section{B. Process of training young athlete calls for humanistic quality education}

The athletic training of young athletes is a long process, and humanistic quality education is also a long-term and systematic project. In this long period of practice, young athletes are undoubtedly on the most critical stage to grow in physical, intellectual, and technical reserves, and each angle of them has a strong plasticity. Therefore, it is the most important stage for the implementation of ideological and working style construction, the promotion of psychological quality and the strengthening of individual behavior education. It will undoubtedly benefit them in their whole life to consolidate the foundation of young athletes' 
humanistic quality at this stage. Obviously, we must seize this opportunity to strengthen the humanistic quality education of young athletes, to cultivate their noble moral sentiment, to make them foster patriotism, and from the heart to refuse the erosion of social unhealthy trends. Besides, we also should make use of this chance to let young athletes form a good psychological quality and habits, and develop good basic accomplishment and consciousness when they are young, such as the spirits of communicating with others, solidarity and cooperation, and courageously striving for success, in order to lay a good foundation for succeeding in characters or skills in the future. Therefore, the process of training young athletes calls for humanistic quality education.

\section{STRATEGIES OF CONSTRUCTING THE PATH OF SCIENTIFIC HUMANISTIC QUALITY EDUCATION FOR YOUNG ATHLETES}

The construction of the path of humanistic quality education for young athletes, in addition to grasping the context of the times and analyzing the actual situation of the development of competitive sports schools, should also follow the following strategies:

\section{A. It should have independence and permeability}

Similar to the primary and secondary schools, the task of humanistic quality education in the curriculum system of competitive sports schools is basically completed by cultural courses [5]. However, unlike those common schools, the scope of cultural courses in competitive sports schools is relatively narrow, and there are some problems in the contents of humanities quality education such as less species, less content and poor realistic planning. In the primary and secondary schools, the enhancement of humanistic quality education can be carried out in three forms: basic cultural courses, humanistic quality courses, and kinds of activities and lectures. Taking into account the particularity of running schools and the professionalism of young athletes in competitive sports schools, the effective way of humanistic quality education should be based on culture teaching, sports training, and various activities and lectures. Although culture teaching and sports training are relatively independent and even antagonistic, the humanistic spirit and competitive spirit are interlinked. Therefore, the humanistic quality education and the training of competitive special skills are interpenetrative from the deepest level. At present, many sports schools only pay attention to the training of competitive special skills, but they often do not focus on guiding young athletes to master the training methods and to form correct value consciousness [6]. It not only lacks the attention to innovative ideas and solidarity spirit, but also lacks the attention to the formation of the competitive concept and the cultivation of individual excellent moral quality. In fact, it is also necessary to integrate the related contents of humanistic quality education into the sports training, which can further promote young athletes to form the excellent competitive qualities and basic qualities, and to master the good ideological and moral qualities and good learning skills.

\section{B. It should be persistent and long-term}

Education is undoubtedly a long-term and continuous process, and this is especially true of the humanistic quality education [7]. In view of the fact that young athletes are relatively small, and that their levels of knowledge, socialization, and psychology are narrower, their outlooks on the world, life, and values are not yet finalized, and their minds and thoughts are in a changeable period. Affected by the above factors, coupled with the daily hard training, there is a certain degree of difficulty in implementing a comprehensive humanistic quality education for this group. However, it is because the group is in a changeable period that it shows the importance of the quality education, especially the humanistic quality education. Education comes into the effect after the hundred years of work. Therefore, educators must be aware of it that the humanistic quality education cannot be accomplished at one stroke. It should be carried out into the process of the lifelong training of athletes, and should continue to strengthen it. Besides, the school, society and family should be involved in this educational project.

\section{SUMMARY}

This study is from three aspects of " the lack of humanistic quality education", "why to carry out humanistic quality education" and "how to carry out humanistic quality education", and then puts forward the path of humanistic quality education for Chinese young athletes. Of course, competitive sports should pay more attention to the process of educating people, rather than simply making tools for winning. In the process of training young athletes, good sports results should not be realized at the expense of the quality educations of ideology, culture, psychology, ability, and so on. Competitive sports should not forget that young athletes are thinking, emotional, sophisticated, and biological individuals. And competitive sports should take human as the starting point, take the all-round development of young athletes as the goal, and make the humanistic quality education run through the whole process.

\section{ACKNOWLEDGMENT}

This work was supported in part by the Project of the Fundamental Research Funds for the Central Universities under Grant LGZD201709, in part by the Project of China Postdoctoral Science Foundation under Grant 2017M611849, in part by Jiangsu Qing LAN Project under Grant 2017, and in part by Nanjing Forest police College Teaching Reform Project under Grant ZD17001 \& YB17001. 


\section{REFERENCES}

[1] YAN Zhong-jie, Discussion on the training idea of young football players from the "four angle training model" of British football, Teaching \& Learning of Physical Education, vol. 11, pp. 64-65, November 2016. ( In Chinese)

[2] LIN Hua, HE Ye-heng, Inspirations of John Dewey's Educational Thoughts to the Cultivation of Young athletes in China, Journal of Nanjing Institute of Physical Education (Social Sciences), vol. 6, pp. 1-4, February 2015 . (In Chinese)

[3] XU Jie, QIN Yang, ZHANG Na, LI Ben, Analysis and Reflection on the lack of humanistic quality of young athletes in Tianjin, Sport, vol. 11, pp. 27-28, July 2016. ( In Chinese)

[4] NI Ya-juan, Discussion on How to Strengthen the Humanistic Quality Education of the Student Athletes, Zhejiang Sport Science, vol. 15, pp. 46-49, March 2013. ( In Chinese)

[5] YANG Hao, YUAN Yan, The Culture Quality Education of Athletes, Journal of Jilin Institute of Physical Education, vol. 2, pp. 145-146, June 2011. ( In Chinese)

[6] LI Yue-jin, Analysis on the development of athletes' humanity quality in their athletic training, Journal of Physical Education, vol. 21, pp. 110-112, January 2003 . ( In Chinese)

[7] WANG Fang, Drawing on the concept of general education to strengthen the humanistic quality of college athletes, Sports Time, vol. 13, pp. 175-176, June 2015. ( In Chinese) 